ARTICLE

DOI: $10.1038 / s 41467-018-04949-4$

\title{
Polyaniline-intercalated manganese dioxide nanolayers as a high-performance cathode material for an aqueous zinc-ion battery
}

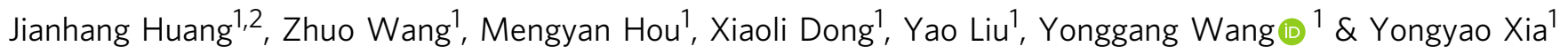

Rechargeable zinc-manganese dioxide batteries that use mild aqueous electrolytes are attracting extensive attention due to high energy density and environmental friendliness. Unfortunately, manganese dioxide suffers from substantial phase changes (e.g., from initial $\alpha-, \beta-$, or $\gamma$-phase to a layered structure and subsequent structural collapse) during cycling, leading to very poor stability at high charge/discharge depth. Herein, cyclability is improved by the design of a polyaniline-intercalated layered manganese dioxide, in which the polymerstrengthened layered structure and nanoscale size of manganese dioxide serves to eliminate phase changes and facilitate charge storage. Accordingly, an unprecedented stability of 200 cycles with at a high capacity of $280 \mathrm{~mA} \mathrm{~h}^{-1}$ (i.e., $90 \%$ utilization of the theoretical capacity of manganese dioxide) is achieved, as well as a long-term stability of 5000 cycles at a utilization of $40 \%$. The encouraging performance sheds light on the design of advanced cathodes for aqueous zinc-ion batteries.

\footnotetext{
${ }^{1}$ Department of Chemistry and Shanghai Key Laboratory of Molecular Catalysis and Innovative Materials, Institute of New Energy, iChEM (Collaborative Innovation Center of Chemistry for Energy Materials) Fudan University, 200433 Shanghai, China. ${ }^{2}$ School of Materials Science and Engineering, Nanchang Hangkong University, 330063 Nanchang, China. Correspondence and requests for materials should be addressed to Y.W. (email: ygwang@fudan.edu.cn)
} 
$\mathrm{n}$ light of pressing concerns regarding environmental pollution and climatic deterioration associated with the combustion of fossil fuels, building a low-carbon society that is based on renewable energy sources has gained widespread attention. However, the utilization of renewable energy sources such as wind and solar requires a safe, green, economic, and efficient electrochemical energy conversion system that can accommodate/ smoothen the intermittency of renewable power ${ }^{1-4}$. As a result, aqueous $\mathrm{Li}^{+}\left(\right.$or $\left.\mathrm{Na}^{+}\right)$batteries are attracting extensive attention due to safety and environmentally friendliness that arise from the use of mild aqueous electrolytes containing $\mathrm{Li}^{+}\left(\text {or } \mathrm{Na}^{+}\right)^{5-16}$. Unfortunately, electrode materials for $\mathrm{Li}^{+}$(or $\mathrm{Na}^{+}$) storage in aqueous electrolytes generally suffer from low capacity $(<150$ $\left.\mathrm{mA} \mathrm{h} \mathrm{g})^{-1}\right)^{5-16}$, which should be remedied with large-scale energy storage. In such situations, the electrode materials for $\mathrm{Zn}^{2+}$ storage in mild aqueous electrolytes have entered researchers' spotlight. For example, copper hexacyanoferrate ${ }^{17,18}, \mathrm{~V}_{2} \mathrm{O}_{5}{ }^{3,19,20}$, and $\mathrm{MnO}_{2}^{21-25}$ have been recently reported for $\mathrm{Zn}^{2+}$ storage. Among these materials, $\mathrm{MnO}_{2}$ attracts much attention because of its high theoretical capacity $\left(308 \mathrm{~mA} \mathrm{~h} \mathrm{~g}^{-1}\right)$, low cost, and low toxicity ${ }^{23-25}$. As the most widespread primary battery, $\mathrm{Zn}-\mathrm{MnO}_{2}$ alkaline battery has been commercialized for a very long time. However, the development of rechargeable $\mathrm{Zn}-\mathrm{MnO}_{2}$ battery was dramatically hindered by the poor reversibility of $\mathrm{MnO}_{2}$ in alkaline electrolyte 26,27 .

Recently, the reversible $\mathrm{Zn}^{2+}$ and/or $\mathrm{H}^{+}$insertion into a $\mathrm{MnO}_{2}$ host in a mild aqueous electrolyte was demonstrated ${ }^{21-25}$, triggering enthusiasm for the development of a rechargeable $\mathrm{Zn}-\mathrm{MnO}_{2}$ battery using a mild aqueous electrolyte. Various manganese dioxide phases, including $\alpha-\mathrm{MnO}_{2}{ }^{22,23,28-31}, \beta-\mathrm{MnO}_{2}{ }^{24}, \gamma-\mathrm{MnO}_{2}{ }^{32}, \delta-\mathrm{MnO}_{2}{ }^{33}$, spinel-type $\mathrm{MnO}_{2}{ }^{34}$, and other types ${ }^{35-37}$, have been reported as host materials for $\mathrm{Zn}^{2+} / \mathrm{H}^{+}$insertion in a mild aqueous electrolyte. However, no matter what the original architecture is, the $\mathrm{MnO}_{2}$ hosts suffer serious structural transformation during cycling processes and transform into layered manganese oxide phases with interlaminar water molecules ${ }^{24,31,32}$ (Supplementary Fig. 1). The formation of the layered structure should be attributable to manganese dissolution and the insertion of hydrated $\mathrm{Zn}^{2+}$ (i.e., $\left[\mathrm{Zn}\left(\mathrm{H}_{2} \mathrm{O}\right)_{6}\right]^{2+}$ ) and $\mathrm{H}^{+}$(i.e., $\mathrm{H}_{3} \mathrm{O}^{+}$) (see Supplementary Fig. 1 and Supplementary Note 1$)$. With coordinated water molecules, the strong electrostatic repulsion between $\mathrm{Zn}^{2+}$ $\left(\right.$ or $\left.\mathrm{H}^{+}\right)$and the host material can be diminished effectively ${ }^{19,31}$. That is to say, theoretically, that the layered structure with $1 \times \infty$ tunnels and extended interlayer spacing are advantageous for the storage of guest-hydrated cations. However, during the phasechange process (i.e., from $\alpha$-, $\beta$-, $\gamma$-phase to layered structure with interlaminar water), large volumetric change leads to significant capacity fading ${ }^{24}$. In addition, with the insertion of a large amount of hydrated cations, the layered structure of manganese oxide will collapse during the charge/discharge process ${ }^{33,35}$, which aggravates capacity fading. As a result, when cycled with high charge/discharge depth, the $\mathrm{MnO}_{2}$ electrode generally exhibits very poor stability. Up to the present, the stable cycling of a $\mathrm{MnO}_{2}$ electrode with the utilization of $>90 \%\left(\sim 277 \mathrm{~mA} \mathrm{~h} \mathrm{~g}^{-1}=\right.$ $\left.308 \mathrm{~mA} \mathrm{~h} \mathrm{~g}^{-1} \times 90 \%\right)$ has never been reported, to the best of our knowledge. Currently, the best reported cycle life of $\mathrm{MnO}_{2}$ in a mild aqueous electrolyte with high utilization of $84 \%(\sim 260 \mathrm{~mA} \mathrm{~h}$ $\mathrm{g}^{-1}$ ) is 45 cycles, which was achieved by Liu's group ${ }^{23}$. Very recently, Chen et al. demonstrated an improvement to 150 cycles with a lower utilization of $75 \%\left(\sim 230 \mathrm{~mA} \mathrm{~h} \mathrm{~g}^{-1}\right)^{24}$. Although there are some reports about high stability (more than 5000 cycles) of a $\mathrm{MnO}_{2}$ cathode in a mild aqueous electrolyte, excellent stability has been achieved with very low utilization of the theoretical capacity for $\mathrm{MnO}_{2}(<30 \%)^{23,25}$. Therefore, it is still a great challenge to efficiently utilize the high capacity of a $\mathrm{MnO}_{2}$ cathode in a mild aqueous electrolyte.
As mentioned above, the capacity fading of a $\mathrm{MnO}_{2}$ cathode arises from both the phase transformation and the instability of $\mathrm{H}_{2} \mathrm{O}$-intercalated layered structure. Directly using the layered $\mathrm{MnO}_{2}$ as an electrode material, which can avoid phase transformations while intercalating a guest polymer into $\mathrm{MnO}_{2}$, to strengthen the extended layered structure is a promising solution. Here we prepare the polyaniline (PANI)-intercalated $\mathrm{MnO}_{2}$ nanolayers through an interface reaction. The nanoscale size of the layered $\mathrm{MnO}_{2}$ and the guest polymer in the interlayer efficiently facilitates the charge storage and strengthen the extended layered structure, and thus as-prepared PANI-intercalated $\mathrm{MnO}_{2}$ nanolayers exhibit high-rate capability and a long cycling life. Even with a high utilization of $90 \%\left(\sim 280 \mathrm{~mA} \mathrm{~h} \mathrm{~g}^{-1}\right)$, the PANIintercalated $\mathrm{MnO}_{2}$ nanolayers still display a very stable cycling performance, which is superior to previous reports. Furthermore, a detailed investigation is performed to clarify the co-insertion mechanism of $\mathrm{Zn}^{2+}$ and $\mathrm{H}^{+}$.

\section{Results}

Structural characterization. The PANI-intercalated $\mathrm{MnO}_{2}$ is prepared by a simple one-step inorganic/organic interface reaction (Fig. 1a), which was developed by our group ${ }^{38}$. At the interface of the organic phase (i.e., $\mathrm{CCl}_{4}$-containing aniline monomer) and the inorganic phase (i.e., $\mathrm{KMnO}_{4}$ aqueous solution), the chemical oxidation polymerization of aniline and the reduction of $\mathrm{MnO}_{4}{ }^{2-}$ occur simultaneously, facilitating the layerby-layer assembly of the layered manganese dioxide and polyaniline (Fig. 1a). Furthermore, the diffusion of aniline from the organic phase to the inorganic phase and the production of PANI restrict the growth of $\mathrm{MnO}_{2}$ to two dimensions. Finally, the PANI-intercalated $\mathrm{MnO}_{2}$ nanolayers gather together to form a mesoporous structure. Figure $1 \mathrm{~b}$ presents the scanning electron microscopy (SEM) image of the as-prepared sample, showing a grainy morphology that comprises aggregates of primary particles. Examination of transmission electron microscopy (TEM) data shown in Fig. 1c indicates that the PANI-intercalated $\mathrm{MnO}_{2}$ nanolayers composite exhibits a spongiform structure. The diffraction rings obtained from selected-area electron diffraction (SAED) analysis (inset of Fig. 1c) indicate polycrystalline character of the sample. The high-resolution transmission electron microscopy (HR-TEM) image (Fig. 1d) reveals that the PANIintercalated $\mathrm{MnO}_{2}$ nanolayers possess a typical size around $10 \mathrm{~nm}$ and a distinct mesoporous structure, and the $\mathrm{MnO}_{2}$ nanolayers show an expanded interlayer space $(\sim 1.0 \mathrm{~nm})$. The mesoporous structure is further supported by an obvious hysteresis loop in the nitrogen adsorption-desorption isotherms (Supplementary Fig. 2a), which indicate a large surface area of $277 \mathrm{~m}^{2} \mathrm{~g}^{-1}$ and a pore size that is mainly centered at $4 \mathrm{~nm}$ (Supplementary Fig. 2b). It should be noted that the layered structure of the $\mathrm{MnO}_{2}$ is not very apparent in Fig. 1d because of the shielding of PANI. In order to clarify this point, the PANI-intercalated $\mathrm{MnO}_{2}$ composite was heat treated at $400{ }^{\circ} \mathrm{C}$ in air for several minutes to obtain a clear view of the intercalated structure (Fig. 1e). After heat treatment to partially remove the shielding of PANI, the expanded interlayer space can be clearly detected in Fig. 1e. Certainly, the result of Fig. 1e also demonstrates that heat treatment at $400{ }^{\circ} \mathrm{C}$ did not destroy the expanded layer structure, indicating a good structure stability of the PANI-intercalated $\mathrm{MnO}_{2}$ nanolayers. The PANI in the composite was characterized with Fourier transform infrared (FT-IR) spectroscopy (Supplementary Fig. 3), and the weight percentage of PANI (5 wt\%) was determined with thermogravimetric (TG) analysis (Supplementary Fig. 4). The broad peaks in the powder X-ray diffraction (XRD) pattern of the PANI-intercalated $\mathrm{MnO}_{2}$ nanolayers composite could be indexed to layered birnessite $\mathrm{MnO}_{2}$ (JCPDS 

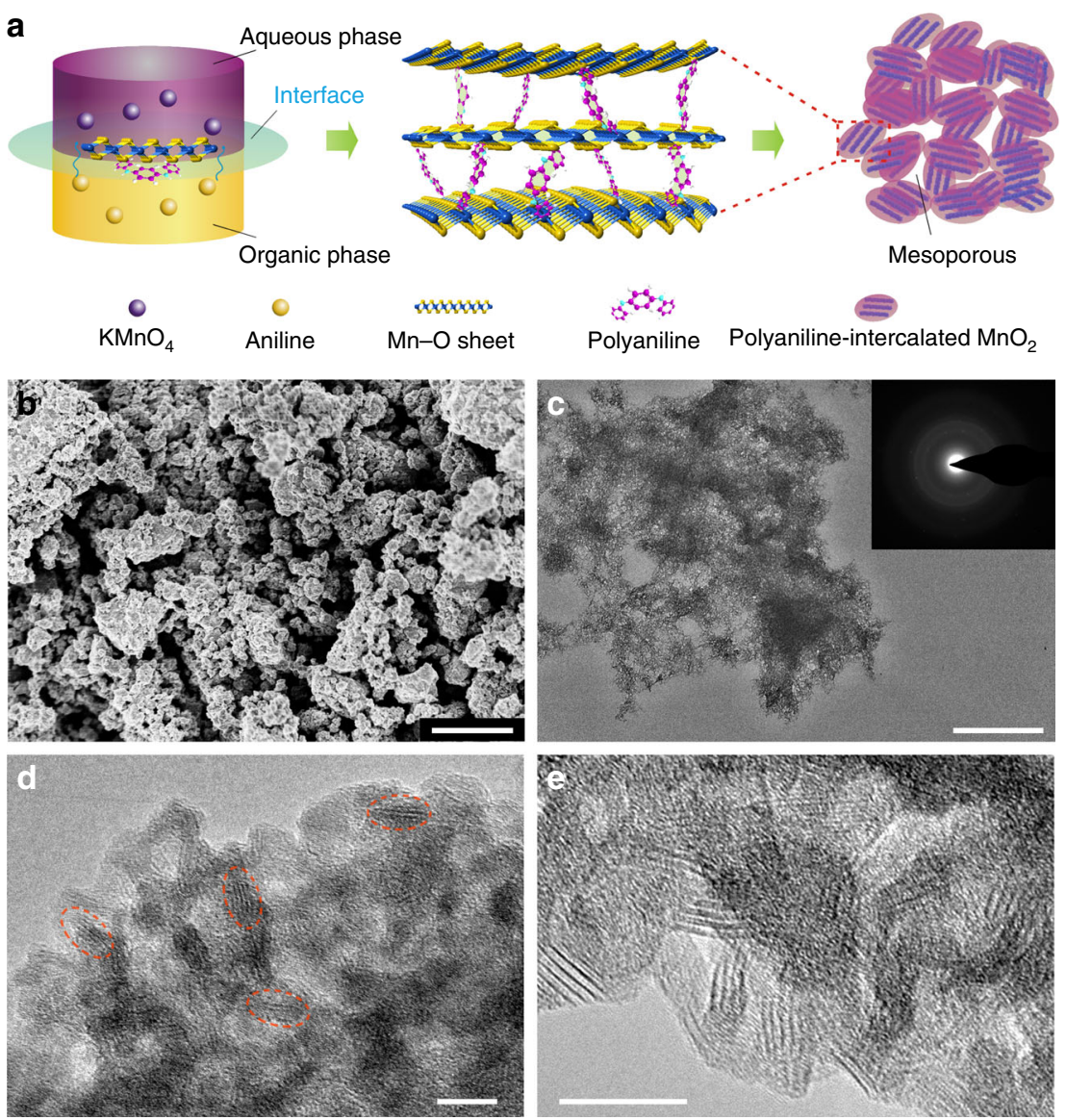

Fig. 1 Preparation and characterization of the polyaniline-intercalated $\mathrm{MnO}_{2}$ nanolayers. a Schematic illustration of expanded intercalated structure of polyaniline (PANI)-intercalated $\mathrm{MnO}_{2}$ nanolayers. b Scanning electron microscopy image, $\mathbf{c}$ transmission electron microscopy (TEM) image (the inset

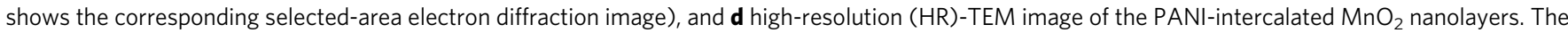
red dashed outlines are used to clarify the morphology profile and particle size of the $\mathrm{MnO}_{2}$ nanolayers. e HR-TEM image of the PANI-intercalated MnO nanolayers with heat treatment at $400^{\circ} \mathrm{C}$ to remove the shield of PANI. Scale bars, b $1 \mu \mathrm{m} ; \mathbf{c} 500 \mathrm{~nm}$, and d, e $10 \mathrm{~nm}$, respectively

13-0105), as shown in Supplementary Fig. 5. X-ray photoelectron spectroscopy (XPS) (Supplementary Fig. 6) shows a spin-energy separation of $4.81 \mathrm{eV}$ for the $\mathrm{Mn} 3 \mathrm{~s}$ doublet in the PANIintercalated $\mathrm{MnO}_{2}$ nanolayers, indicating 4.0 charge state of $\mathrm{Mn}$ in the composite 39,40 .

Electrochemical characterization. The electrochemical profile of the PANI-intercalated $\mathrm{MnO}_{2}$ nanolayers composite is characterized by the typical coin-type cell, which is composed of a PANIintercalated $\mathrm{MnO}_{2}$ composite cathode, a $\mathrm{Zn}$ foil anode, and an aqueous electrolyte $\left(2 \mathrm{M} \mathrm{ZnSO}_{4}+0.1 \mathrm{M} \mathrm{MnSO}_{4}\right)$ adsorbed with a glass fiber separator. According to Liu's report ${ }^{23}$, the presence of $0.1 \mathrm{M} \mathrm{MnSO}_{4}$ could inhibit the dissolution of $\mathrm{Mn}^{2+}$ (from $\mathrm{Mn}^{3+}$ disproportionation) into the electrolyte. Furthermore, the presence of $\mathrm{Mn}^{2+}$ can improve the Zn-platting/stripping efficiency (Supplementary Fig. 7). Figure 2a shows the cyclic voltammetry (CV) data for the PANI-intercalated $\mathrm{MnO}_{2}$ nanolayers composite. There is an obvious cathodic peak around $1.23 \mathrm{~V}$ during the first cathodic sweep, while the corresponding anode peak appears around $1.56 \mathrm{~V}$ during the anodic sweep. In the following cycles, the strengths of the redox peaks mentioned above gradually decrease; meanwhile, one new pair of redox peaks emerge around 1.38 and $1.60 \mathrm{~V}$. The two-step charge storage should be attributed to the different insertion mechanism of $\mathrm{H}^{+}$and/or $\mathrm{Zn}^{2+}$ during the discharge process, which will be further clarified in the mechanism investigation. The galvanostatic charge/discharge profile of the PANI- intercalated $\mathrm{MnO}_{2}$ nanolayers composite is shown in Fig. 2b, where the applied current density and the achieved capacity are calculated by mass loading of PANI-intercalated $\mathrm{MnO}_{2}$ nanolayers composite in the cathode (i.e., $2 \mathrm{mg} \mathrm{cm}^{-2}$ with an electrode area of $1 \mathrm{~cm}^{-2}$ ). When tested at the low current of $50 \mathrm{~mA} \mathrm{~g}^{-1}(0.16 \mathrm{C})$, the cell exhibits initial discharge capacity of $260 \mathrm{~mA} \mathrm{~h}^{-1}$, involving a slope discharge profile from 1.5 to $1.33 \mathrm{~V}\left(\sim 50 \mathrm{~mA} \mathrm{~h}^{-1}\right.$ capacity) and a consequent discharge platform about $1.36 \mathrm{~V} \quad\left(\sim 210 \mathrm{~mA} \mathrm{~h} \mathrm{~g}^{-1}\right.$ capacity). In the subsequent cycle, the discharge capacity is increased to $298 \mathrm{~mA} \mathrm{~h} \mathrm{~g}^{-1}$, which is close to the theoretical capacity of $308 \mathrm{~mA} \mathrm{~h} \mathrm{~g}^{-1}$ (based on single electron transfer between $\mathrm{Mn}^{4+}$ and $\left.\mathrm{Mn}^{3+}\right)$. Figure $2 \mathrm{c}$ presents the rate performance tested at different current densities, and corresponding cycle profile is given in Fig. 2 d. As shown in Fig. $2 c$, d, the cell exhibits a reversible discharge capacity of $280 \mathrm{~mA} \mathrm{~h} \mathrm{~g}^{-1}$ at the current density of $200 \mathrm{~mA} \mathrm{~g}^{-1}$, which is very close to that achieved at the low current density of $50 \mathrm{~mA} \mathrm{~g}^{-1}$. Even at the high current density of $3000 \mathrm{~mA} \mathrm{~g}^{-1}$, the cell still can deliver a capacity of $110 \mathrm{~mA} \mathrm{~h} \mathrm{~g}^{-1}$, which is to the best of our knowledge among the best rate performances reported to date in this field ${ }^{23-25}$. It should be noted that the two discharge plateaus evolve to a single one at the high rate, which should be attributable to $\mathrm{H}^{+}$insertion that dominates the discharge process at high rate. This phenomenon can be explained by the faster $\mathrm{H}^{+}$insertion than $\mathrm{Zn}^{2+}$ insertion, which will be confirmed by the later electrochemical impedance measurements. Cycle stability of the PANI-intercalated $\mathrm{MnO}_{2}$ composite was evaluated at the current densities of 200 and 

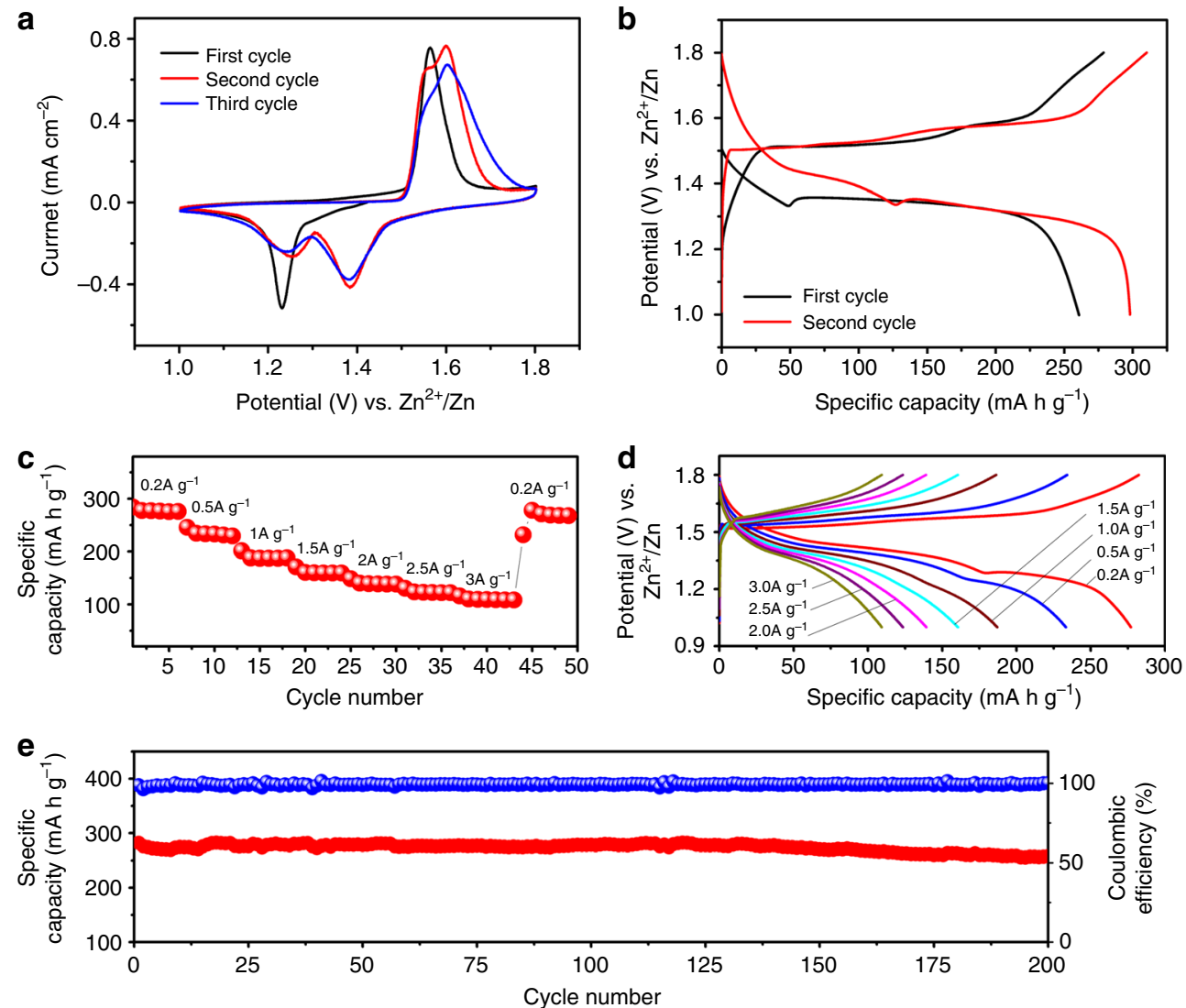

Fig. 2 Electrochemical performance of polyaniline-intercalated $\mathrm{MnO}_{2}$ nanolayers. a Cyclic voltammetry curves of the coin-type cell ( $\mathrm{Zn} /$ polyaniline (PANI)intercalated $\mathrm{MnO}_{2}$ ) using $2 \mathrm{M} \mathrm{ZnSO}_{4}+0.1 \mathrm{M} \mathrm{MnSO}_{4}$ aqueous electrolyte at $0.1 \mathrm{mV} \mathrm{s}^{-1}$. b Typical galvanostatic charge/discharge curves at $50 \mathrm{~mA} \mathrm{~g}^{-1}$ between 1.0 and $1.8 \mathrm{~V}$ of the cell. $\mathbf{c}$, $\mathbf{d}$ Rate performance and charge/discharge profiles of the cell tested with the charge/discharge current densities varying from 200 to $3000 \mathrm{~mA} \mathrm{~g}^{-1}$. e Cycling performance in terms of specific capacity (red) and the corresponding coulombic efficiency (blue) at a current density of $200 \mathrm{~mA} \mathrm{~g}^{-1}$

$2000 \mathrm{~mA} \mathrm{~g}^{-1}$. From Fig. 2e, it can be seen that PANI-intercalated $\mathrm{MnO}_{2}$ nanolayers composite delivers $280 \mathrm{~mA} \mathrm{~h} \mathrm{~g}^{-1}$ capacity for 200 cycles with coulombic efficiency around $100 \%$, in which an ultra-high utilization of more than $90 \%$ (based on theoretical capacity of $308 \mathrm{~mA} \mathrm{~h} \mathrm{~g}^{-1}$ of $\mathrm{MnO}_{2}$ ) is obtained. To the best of our knowledge, it is the highest utilization that can be stable for 200 cycles in an aqueous zinc-ion battery (see Supplementary Table 1 for detailed information). The charge/discharge curves at different cycles are shown in Supplementary Fig. 8 to clarify the potential evolution during the cycling test, where a slight potential evolution over 200 cycles can be detected. When tested at the high current density of $2000 \mathrm{mAg}^{-1}$, the PANIintercalated $\mathrm{MnO}_{2}$ nanolayers composite present a stable discharge capacity of around $125 \mathrm{~mA} \mathrm{~h} \mathrm{~g}^{-1}$ (up to $40 \%$ utilization) over 5000 cycles (Supplementary Fig. 9). The stable cycle life of 5000 cycles with the utilization of $40 \%$ is superior to previous reports (see Supplementary Table 2 for detailed information). The superior performance is largely attributable to the reinforcement of the layered structure with intercalated PANI, which avoids phase transformation and collapse of the layered structure during repeated insertion/extraction of hydrated cations. Simultaneously, the presence of $\mathrm{Mn}^{2+}$ in the electrolyte also alleviates the $\mathrm{Mn}^{2+}$ dissolution-induced capacity fading 23,24 .

To further demonstrate the function of the PANI-reinforced layered structure, the cycling performance of the PANIintercalated $\mathrm{MnO}_{2}$ nanolayers composite was also investigated using the $\mathrm{ZnSO}_{4}$ electrolyte without $\mathrm{Mn}^{2+}$ (Supplementary Fig. 10), and the corresponding result was compared with previous reports about $\mathrm{MnO}_{2}$ cycled in the electrolyte without $\mathrm{Mn}^{2+}$ (see Supplementary Table 3). On the other hand, it should be noted that the high cycle performance shown in Fig. 2e or Supplementary Fig. 9 is achieved by using excess Zn-anode (see Method section). The purpose is to exclude the effect of $\mathrm{Zn}$-anode fading, which is similar with previous reports about $\mathrm{MnO}_{2}$ cathode $^{22-36}$. SEM images of the cycled $\mathrm{Zn}$ electrode and PANIintercalated $\mathrm{MnO}_{2}$ electrode are given in Supplementary Fig. 11 and Supplementary Fig. 12, respectively. In practical application, the issue of $\mathrm{Zn}$-anode is another obstacle for $\mathrm{Zn}$-ion batteries. The modification of an electrode developed by La Mantia et $\mathrm{al}^{41}$. and the electrolyte optimization reported by Chen's group ${ }^{42}$ may be the potential solutions to improve the stability of $\mathrm{Zn}$-anode.

Reaction mechanism. Until now, two reaction mechanisms for a manganese dioxide cathode, involving $\mathrm{Zn}^{2+}$ and $\mathrm{H}^{+}$insertion/ extraction, respectively, have been reported ${ }^{23-25,31}$. Due to various crystallographic polymorphs of manganese dioxide, the reaction mechanism during cycling in neutral aqueous electrolytes remains a topic of discussion. Here the insertion mechanism was investigated to better understand the electrochemical reaction during cycling. Ex situ XRD analysis of the PANI-intercalated

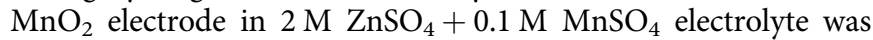
conducted during the charge/discharge cycle within the potential window of $1.0-1.8 \mathrm{~V}$ at a current density of $50 \mathrm{~mA} \mathrm{~g}^{-1}$ (Fig. 3a and Supplementary Fig. 13). During the first discharge platform (Region I, red color), only two sets of peaks (related to polytetrafluoroethylene (PTFE) binder at $18^{\circ}$ and Ti current collector 

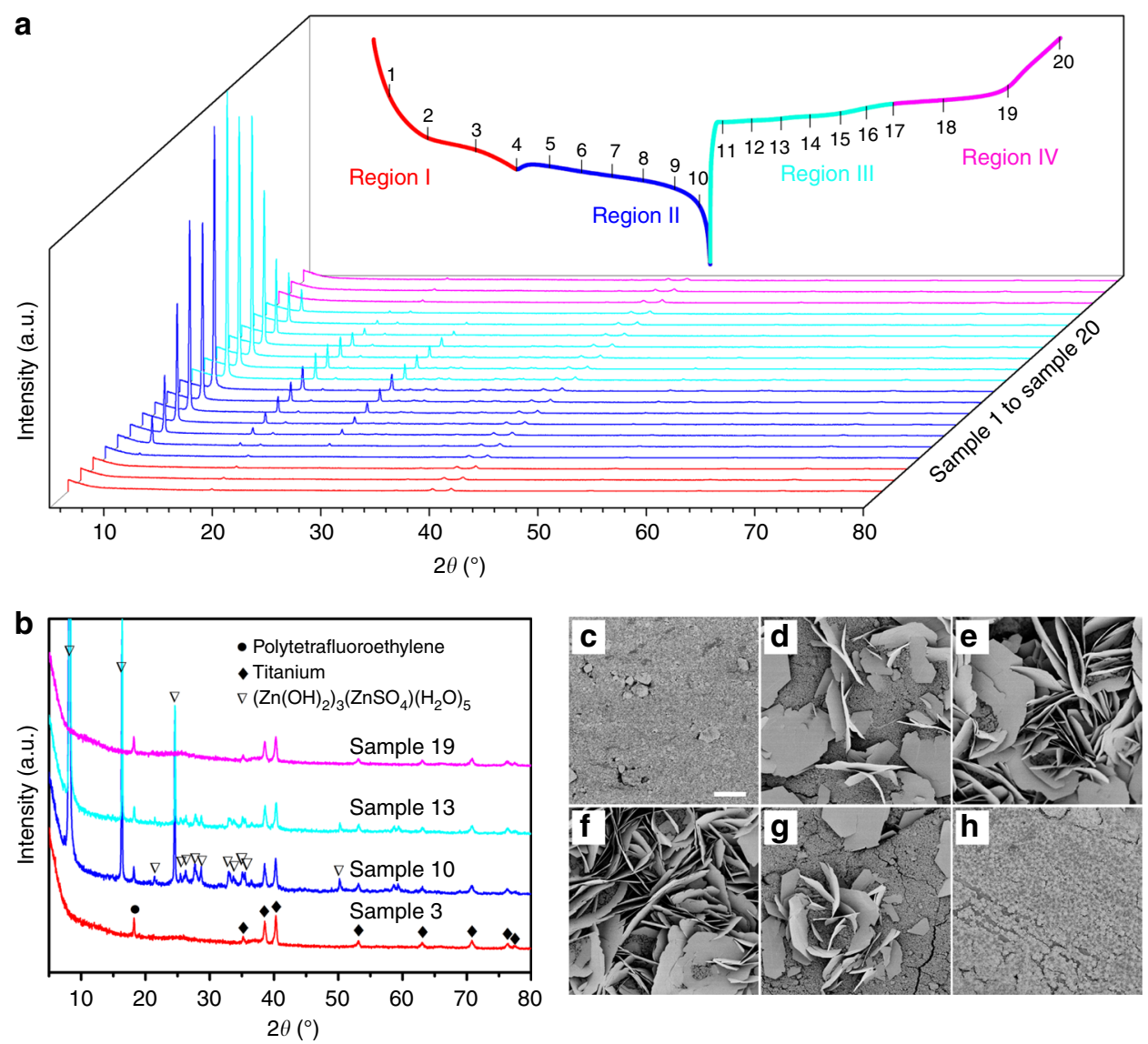

Fig. 3 Structure evolution of polyaniline-intercalated $\mathrm{MnO}_{2}$ electrode during cycling. a Evolution of ex situ X-ray powder diffraction (XRD) patterns during the charge/discharge process (the vertical bars denoted with consecutive numbers indicate the locations where the XRD patterns were recorded). b Selected ex situ XRD patterns from a (corresponding to the XRD patterns denoted with 3, 10, 13, and 19 in a), which represent the typical XRD pattern in each corresponding charge/discharge region. c-h Scanning electron microscopy (SEM) images for morphologic evolution of electrode during cycling (the SEM images were taken at the locations indicated by vertical bars 3,5, 10, 12, 16, and 20 in a, respectively). Scale bars, c-h $10 \mu \mathrm{m}$, respectively (the magnification is the same for images $\mathbf{c}-\mathbf{h}$ )

at $38.4^{\circ}$ and $40.2^{\circ}$ ) could be clearly observed, and there is no obvious variation throughout Region I. However, from the beginning of the second discharge platform (Region II, blue color), some new peaks arise, including a very strong peak at $8.1^{\circ}$ and obvious peaks at $16.2^{\circ}$ and $24.4^{\circ} 2 \theta$. During the subsequence charge process, the strength of arisen peaks decreases gradually (Region III, cyan color), and finally recover to the original pattern (Region IV, pink color) which is as same as Region I, indicating a good reversibility of electrode reaction. In order to analyze the evolution more clearly, several selected XRD patterns from Fig. 3a were presented in Fig. 3b. The emerging peaks (including strong peaks at $8.1^{\circ}, 16.2^{\circ}$, and $24.4^{\circ} 2 \theta$ and other subtle peaks highlighted with inverted triangles) are indexed to ( $\mathrm{Zn}$ $\left.(\mathrm{OH})_{2}\right)_{3}\left(\mathrm{ZnSO}_{4}\right)\left(\mathrm{H}_{2} \mathrm{O}\right)_{5}$ (zinc hydroxide sulfate hydrate, JCPDS: $78-0246)^{23}$. The formation of zinc hydroxide sulfate is in consistence with Liu et al.'s report ${ }^{23}$. With the consumption of $\mathrm{H}^{+}$in the electrolyte, the increasing amount of $\mathrm{OH}^{-}$leads to the formation of zinc hydroxide sulfate hydrate. SEM is further conducted to monitor the morphologic evolution of the PANIintercalated $\mathrm{MnO}_{2}$ electrode (Fig. 3c-h). For Region I, there is no obvious change on the electrode surface, but in the Region II, increasingly large flakes emerge with discharging and gradually vanish during subsequent charging. The highly reversible morphologic transformation during the charge/discharge process is well consistent with the evolution observed in XRD patterns. Energy-dispersive spectroscopy (EDS) analysis shows that the flake-like product contains abundant $\mathrm{Zn}$ and $\mathrm{S}$, but no evident
Mn, which supports that the large flakes are zinc hydroxide sulfate hydrate (Supplementary Fig. 14), as indexed in the XRD patterns.

As demonstrated by the above observation, the electrochemical reaction of the PANI-intercalated $\mathrm{MnO}_{2}$ nanolayers composite definitely involved $\mathrm{H}^{+}$insertion, which supports the conclusion by Liu et $\mathrm{al}^{23}$. However, it does not preclude $\mathrm{Zn}^{2+}$ insertion during the discharge process. We presume that besides $\mathrm{H}^{+}$insertion, $\mathrm{Zn}^{2+}$ insertion plays an important role in the discharge process because the two discharge platforms cannot be satisfactorily explained by only $\mathrm{H}^{+}$insertion. Therefore, further investigation was performed to clarify this point. Figure 4a shows the discharge curves of the PANI-intercalated $\mathrm{MnO}_{2}$ nanolayers composite in different electrolytes (red curve: $2 \mathrm{M} \mathrm{ZnSO}_{4}+0.1 \mathrm{M} \mathrm{MnSO}_{4}$, blue curve: $0.1 \mathrm{M}$ $\mathrm{MnSO}_{4}$ ). As we know, PANI-intercalated $\mathrm{MnO}_{2}$ exhibits two discharge platforms in $2 \mathrm{M} \mathrm{ZnSO}_{4}+0.1 \mathrm{M} \mathrm{MnSO}_{4}$ electrolyte (red curve). However, when $\mathrm{Zn}^{2+}$ was eliminated, a single-slope discharge profile was observed for the $0.1 \mathrm{M} \mathrm{MnSO}_{4}$ electrolyte (blue curve). From this result, we preliminarily conclude that the second discharge platform is related to $\mathrm{Zn}^{2+}$ insertion. Raman spectra (Fig. 4b) are used to further characterize $\mathrm{Zn}^{2+}$ insertion/ extraction during charge/discharge states. A band of around $650 \mathrm{~cm}^{-1}$ can be observed throughout the whole charge/discharge process, which is attributed to the symmetric stretching vibration $(\mathrm{Mn}-\mathrm{O})$ of the $\mathrm{MnO}_{6}$ groups ${ }^{43,44}$. In addition, a pair of peaks between 300 and $400 \mathrm{~cm}^{-1}$ that are derived from $\mathrm{Zn}-\mathrm{O}$ vibrations ${ }^{45,46}$ arise after discharge to $1 \mathrm{~V}$ and then vanish after 

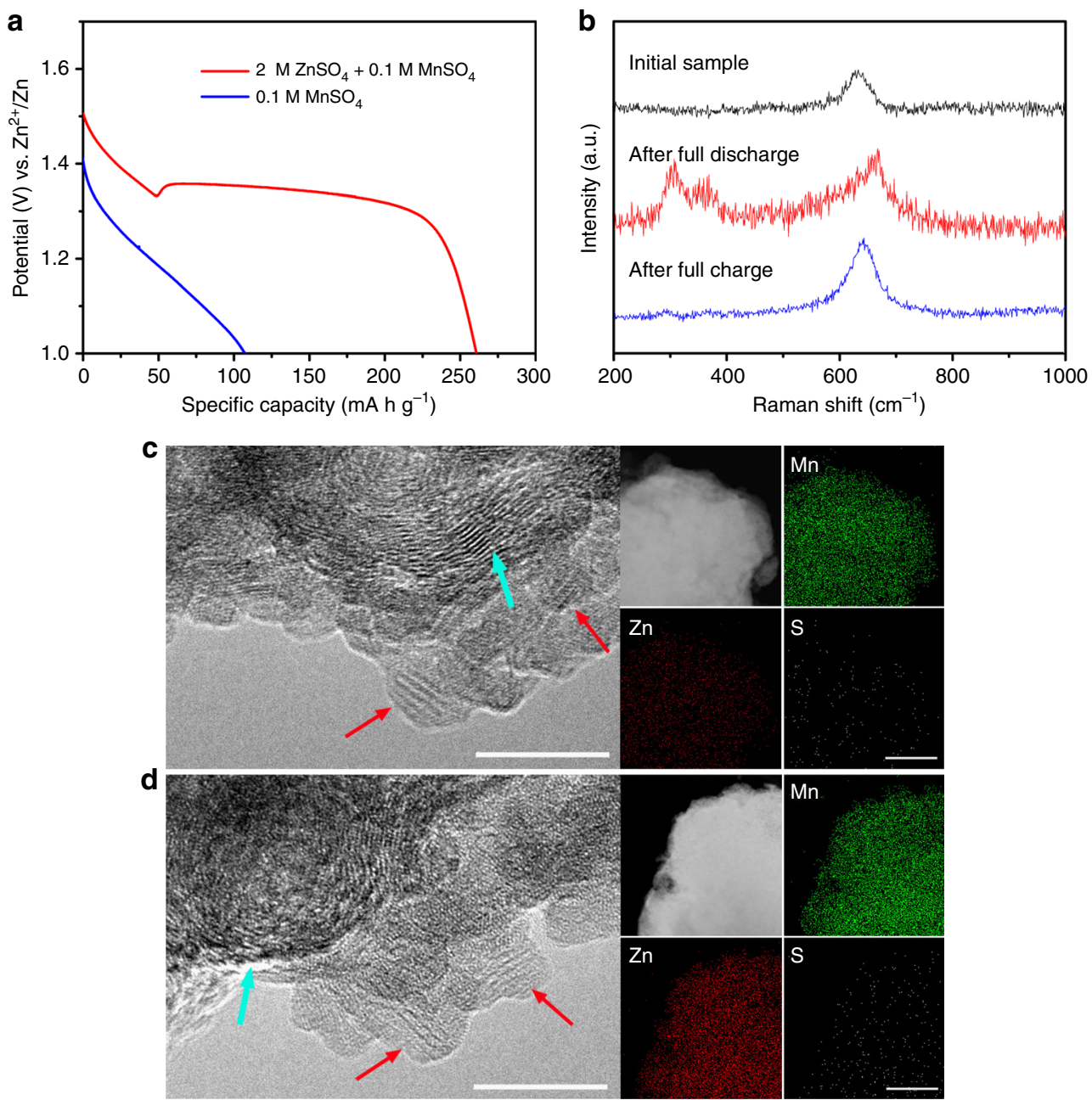

Fig. 4 Characterization of sequential insertion of $\mathrm{H}^{+}$and $\mathrm{Zn}^{2+}$ during two discharge platforms. a The discharge profile of polyaniline (PANI)-intercalated $\mathrm{MnO}_{2}$ electrode at current density of $50 \mathrm{mAg}^{-1}$ in different electrolytes (red curve: $2 \mathrm{M} \mathrm{ZnSO}_{4}+0.1 \mathrm{M} \mathrm{MnSO}_{4}$, blue curve: $0.1 \mathrm{M} \mathrm{MnSO}$ ). b Raman spectra of PANI-intercalated $\mathrm{MnO}_{2}$ electrode after full discharge and full charge. $\mathbf{c}$ High-resolution transmission electron microscopy (HR-TEM) image of the testing electrode after the first discharge platform and the corresponding scanning transmission electron microscopy-energy dispersive spectroscopy (STEM-EDS) mappings for elements like Mn, Zn, and S. d HR-TEM image of the testing electrode after the second discharge platform and the corresponding STEM-EDS mappings for elements like $\mathrm{Mn}, \mathrm{Zn}$, and $\mathrm{S}$. Red arrows indicate the PANI-intercalated $\mathrm{MnO}_{2}$ nanolayers and cyan arrows indicate the acetylene black in electrode. Scale bars, $\mathbf{c}, \mathbf{d} 10 \mathrm{~nm}$ for TEM images and $100 \mathrm{~nm}$ for STEM-EDS mapping images

consequent charging. This reversible $\mathrm{Zn}-\mathrm{O}$ band demonstrates the insertion/extraction of $\mathrm{Zn}^{2+}$ in the PANI-intercalated $\mathrm{MnO}_{2}$ electrode. The conclusion is supported by the observation of $\mathrm{Zn}$ on the electrode surface with scanning electron microscopy-energy dispersive X-ray spectroscopy (SEM-EDX) analysis after discharge (Supplementary Fig. 15). Moreover, the kinetic behavior during the first and second discharge platform was investigated with electrochemical impedance spectroscopy (EIS, Supplementary Fig. 16), in which the calculated diffusion coefficient in the first discharge platform $\left(5.84 \times 10^{-12} \mathrm{~cm}^{2} \mathrm{~s}^{-1}\right)$ is much higher than that in the second discharge platform $\left(7.35 \times 10^{-14} \mathrm{~cm}^{2} \mathrm{~s}^{-1}\right)$, indicating different insertion ions during the two different discharge platforms.

HR-TEM was further employed to gain insight into the structure evolution during the two-stage discharge process. As seen in Fig. 4c, after the first discharge platform, the layered structure with large lattice spacing (see red arrows) is maintained (the cyan arrow indicates the acetylene black in the electrode), and the corresponding scanning transmission electron microscopy-energy dispersive spectroscopy (STEM-EDS) mapping reveals abundant $\mathrm{Mn}$, trace amounts of $\mathrm{Zn}$, and negligible $\mathrm{S}$ in the discharge products, indicating $\mathrm{H}^{+}$insertion in the initial discharge stage. The layered structure was also preserved well after the second discharge platform (Fig. 4d), but unlike the first discharge platform, zinc is abundant with homogeneous distribution in the PANI-intercalated $\mathrm{MnO}_{2}$ nanolayers according to STEM-EDS mapping, confirming $\mathrm{Zn}^{2+}$ insertion into the PANIintercalated $\mathrm{MnO}_{2}$ nanolayers. Notably, the layered structure was preserved after the long cycle test (Supplementary Fig. 17), which strongly demonstrates the high stability of PANI-intercalated $\mathrm{MnO}_{2}$ nanolayers. On the contrary, other $\mathrm{MnO}_{2}$ crystallographic polymorphs suffer severe phase transformation, as reported by previous researchers $24,31,32$.

Based on the above analysis, we propose a co-insertion mechanism of $\mathrm{H}^{+}$and $\mathrm{Zn}^{2+}$ in PANI-intercalated $\mathrm{MnO}_{2}$ nanolayers with a self-regulating function in the electrolyte (Fig. 5). In the first stage of discharge, $\mathrm{H}^{+}$initially inserts into PANIintercalated $\mathrm{MnO}_{2}$ nanolayers, leading to a gradual decrease of $\mathrm{H}^{+}$ concentration in the vicinity of the electrode. During the first discharge platform, the $\mathrm{OH}^{-}$concentration is not high enough to form zinc hydroxide sulfate. With sustained decrease of $\mathrm{H}^{+}$ concentration, the second discharge platform arises, which is caused by a $\mathrm{Zn}^{2+}$ insertion reaction; meanwhile, the amount of zinc hydroxide sulfate formed on the electrode surface increases. Along with the $\mathrm{Zn}^{2+}$ insertion, $\mathrm{H}^{+}$insertion is ongoing in the second 


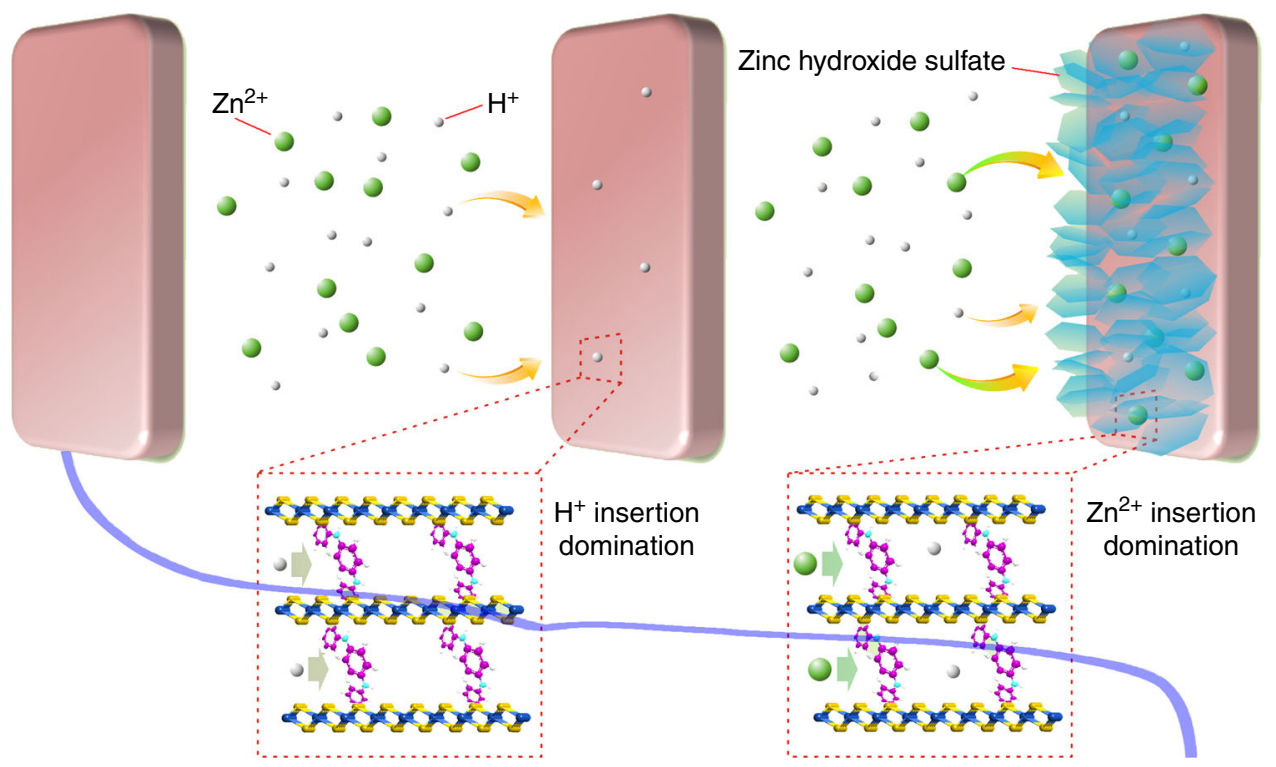

Fig. 5 Diagram showing the sequential insertion of $\mathrm{H}^{+}$and $\mathrm{Zn}^{2+}$. During the first discharge platform, $\mathrm{H}^{+}$insertion into polyaniline (PANI)-intercalated $\mathrm{MnO}_{2}$ nanolayers dominates the electrode reaction, which gradually decreases $\mathrm{H}^{+}$concentration around the electrode. With a sustained decrease of $\mathrm{H}^{+}$, $\mathrm{Zn}^{2+}$ insertion dominates the electrochemical reaction, raising the second discharge platform; meanwhile, the sustained decrease of $\mathrm{H}^{+}$concentration leads to the formation of zinc hydroxide sulfate on the electrode surface

discharge platform, leading to the increased formation of flake-like zinc hydroxide sulfate. Note that this "self-regulation function" consumes superfluous $\mathrm{OH}^{-}$, which is beneficial for high cycle stability. On recharge, the released $\mathrm{H}^{+}$can lead to the dissolution of the zinc hydroxide sulfate.

\section{Discussion}

In summary, PANI-intercalated $\mathrm{MnO}_{2}$ nanolayers were prepared and investigated as the cathode material for a rechargeable $\mathrm{Zn}-\mathrm{MnO}_{2}$ battery using a mild aqueous electrolyte. With the typical nanosize, expanded interlayer space, uniform mesostructure and polymer-reinforced layered structure, the PANIintercalated $\mathrm{MnO}_{2}$ nanolayers show a promising rate performance and an excellent cycling stability at high charge/discharge depth that is superior to previous reports. It is demonstrated that the PANI-reinforced layered structure combined with the nanoparticle-sized $(\sim 10 \mathrm{~nm}) \mathrm{MnO}_{2}$ can efficiently eliminate the hydrated $\mathrm{H}^{+} / \mathrm{Zn}^{2+}$-insertion-induced phase transformation and the subsequent structure collapse, which is of vital significance to obtaining long cycle life along with high capacity utilization. Furthermore, the hydrated $\mathrm{H}^{+} / \mathrm{Zn}^{2+}$ co-insertion process in the layered $\mathrm{MnO}_{2}$ was investigated in detail, and a self-regulating mechanism of electrolyte-involved generation/dissolution of flakelike zinc hydroxide sulfate was clarified. These achievements cast light on the design of more advanced $\mathrm{MnO}_{2}$ cathode materials for rechargeable $\mathrm{Zn}-\mathrm{MnO}_{2}$ batteries using mild aqueous electrolytes.

\footnotetext{
Methods

Material preparation. In a typical synthesis, aniline monomer $(9 \mathrm{~mL}$, Aldrich) was dissolved in $\mathrm{CCl}_{4}$ organic phase $(450 \mathrm{~mL}$, Aldrich) and potassium permanganate $(0.45 \mathrm{~g}$, Aldrich) was dissolved in distilled water $(450 \mathrm{~mL}, \mathrm{pH} 7)$. The solution was mixed to obtain an aqueous/organic stratification system with a clear interface. The reaction system was kept at $5{ }^{\circ} \mathrm{C}$ for $24 \mathrm{~h}$. The chemical oxidation polymerization of aniline and reduction of potassium permanganate occurred simultaneously at the aqueous/organic interface, which is similar to our previous report ${ }^{38}$. By continuous diffusion of aniline from the organic phase to the aqueous phase, layer-by-layer self-assembly of layered manganese dioxide and polymer was established, and the final products were obtained after centrifugation and freeze drying.
}

Characterization. Powder XRD patterns were collected on a X-ray diffractometer (Bruker D8 Advance, Germany) with Cu Ka radiation $(\lambda=0.15406 \mathrm{~nm})$. SEM images and EDX mapping were obtained on Field-emission JEOL JSM-6390 microscope. TEM and EDS mapping were performed on JEOL JEM-2010 microscope. XPS was tested on a Thermo Escalab 250 equipped with a hemispherical analyzer. Raman spectra were obtained on RENISHAW inVia Raman Microscope using $633 \mathrm{~nm}$ excitation. T.G. was measured by a STA209 PC (NETZSCH, Germany) analyzer with an $\mathrm{O}_{2}$ flow. Fourier transform infrared spectroscopy (FT-IR) spectrum was recorded with a NICOLET 6700 FT-IR Spectrometer using KBr pellets.

Electrochemical measurements. Electrochemical measurements were performed with CR2016 coin-type cells. The full cells were assembled using the PANIintercalated $\mathrm{MnO}_{2}$ composite as the cathode, a zinc metal foil as the anode, a glass fiber as separator, and aqueous $2 \mathrm{M} \mathrm{ZnSO}_{4}$ with $0.1 \mathrm{M} \mathrm{MnSO}_{4}$ as electrolyte. The working electrode was fabricated by compressing a mixture of the active materials of PANI-intercalated $\mathrm{MnO}_{2}$ composite, the conductive material (acetylene black, $\mathrm{AB}$ ), and the binder (polytetrafluoroethylene, PTFE) in a weight ratio of active materials/AB/PTFE $=80: 10: 10$ onto a Ti grid at $20 \mathrm{MPa}$. The areal loading density of PANI-intercalated $\mathrm{MnO}_{2}$ is $2.0 \mathrm{mg} \mathrm{cm}^{-2}$, while the counter electrode (Zinc metal foil) is $20 \mathrm{mg} \mathrm{cm}^{-2}$ with the purpose of excluding the effect of $\mathrm{Zn}$-anode fading. Galvanostatic charge/discharge performances were conducted on a battery test system (Neware BTS 4000). Cyclic voltammetry $\left(0.1 \mathrm{mV} \mathrm{s}^{-1}\right)$ and electrochemical impedance spectroscopy (an AC voltage of $5 \mathrm{mV}$ amplitude) measurements were carried out using an AUTOLAB electrochemical work station (PGSTAT 302N). In order to avoid the conglutination between separator and electrode, the electrochemical tests for SEM, TEM, Raman, and XRD analysis were conducted with a simulated battery composed of a working electrode, counter electrode and electrolyte, but no separator.

Data availability. The authors declare that all the relevant data are available within the paper and its Supplementary Information file or from the corresponding author on reasonable request.

Received: 7 February 2018 Accepted: 25 April 2018

Published online: 25 July 2018

\section{References}

1. Armand, M. \& Tarascon, J. M. Building better batteries. Nature 451, 652-657 (2008).

2. Goodenough, J. B. Electrochemical energy storage in a sustainable modern society. Energ. Environ. Sci. 7, 14-18 (2014).

3. Kundu, D., Adams, B. D., Duffort, V., Vajargah, S. H. \& Nazar, L. F. A highcapacity and long-life aqueous rechargeable zinc battery using a metal oxide intercalation cathode. Nat. Energy 1, 16119 (2016).

4. Chu, S. \& Majumdar, A. Opportunities and challenges for a sustainable energy future. Nature 488, 294-303 (2012). 
5. Suo, L. M. et al. "Water-in-salt" electrolyte enables high-voltage aqueous lithium-ion chemistries. Science 350, 938-943 (2015).

6. Luo, J. Y., Cui, W. J., He, P. \& Xia, Y. Y. Raising the cycling stability of aqueous lithium-ion batteries by eliminating oxygen in the electrolyte. Nat. Chem. 2, 760-765 (2010).

7. Pasta, M., Wessells, C. D., Huggins, R. A. \& Cui, Y. A high-rate and long cycle life aqueous electrolyte battery for grid-scale energy storage. Nat. Commun. $\mathbf{3}$, 1149 (2012).

8. Pasta, M. et al. Full open-framework batteries for stationary energy storage. Nat. Commun. 5, 3007 (2014).

9. Li, Q., Li, N., Liu, Y., Wang, Y. \& Zhou, H. High-safety and low-cost photoassisted chargeable aqueous sodium-ion batteries with $90 \%$ input electric energy savings. Adv. Energy Mater. 6, 1600632 (2016).

10. Palomares, V. et al. Na-ion batteries, recent advances and present challenges to become low cost energy storage systems. Energ. Environ. Sci. 5, 5884 (2012).

11. Kim, H. et al. Aqueous rechargeable $\mathrm{Li}$ and $\mathrm{Na}$ ion batteries. Chem. Rev. 114, 11788-11827 (2014).

12. Wang, Y. et al. Ti-substituted tunnel-type $\mathrm{Na}_{0.44} \mathrm{MnO}_{2}$ oxide as a negative electrode for aqueous sodium-ion batteries. Nat. Commun. 6, 6401 (2015).

13. Liang, Y. L. et al. Universal quinone electrodes for long cycle life aqueous rechargeable batteries. Nat. Mater. 16, 841-848 (2017).

14. Li, Z., Young, D., Xiang, K., Carter, W. C. \& Chiang, Y.-M. Towards high power high energy aqueous sodium-ion batteries: the $\mathrm{NaTi}_{2}\left(\mathrm{PO}_{4}\right)_{3} /$ $\mathrm{Na}_{0.44} \mathrm{MnO}_{2}$ system. Adv. Energy Mater. 3, 290-294 (2013).

15. Yan, J. et al. Rechargeable hybrid aqueous batteries. J. Power Sources 216, 222-226 (2012).

16. Yamada, Y. et al. Hydrate-melt electrolytes for high-energy-density aqueous batteries. Nat. Energy 1, 16129 (2016).

17. Trocoli, R. \& La Mantia, F. An aqueous zinc-ion battery based on copper hexacyanoferrate. ChemSusChem 8, 481-485 (2015).

18. Canepa, P. et al. Odyssey of multivalent cathode materials: open questions and future challenges. Chem. Rev. 117, 4287-4341 (2017)

19. Yan, M. et al. Water-lubricated intercalation in $\mathrm{V}_{2} \mathrm{O}_{5} \cdot \mathrm{nH}_{2} \mathrm{O}$ for high-capacity and high-rate aqueous rechargeable zinc batteries. Adv. Mater. 30, 1703725 (2017).

20. He, P. et al. High-performance aqueous zinc-ion battery based on layered $\mathrm{H}_{2} \mathrm{~V}_{3} \mathrm{O}_{8}$ nanowire cathode. Small 13, 1702551 (2017).

21. Xu, C., Du, H., Li, B., Kang, F. \& Zeng, Y. Reversible insertion properties of zinc ion into manganese dioxide and its application for energy storage. Electrochem. Solid ST 12, A61 (2009).

22. Xu, C., Li, B., Du, H. \& Kang, F. Energetic zinc ion chemistry: the rechargeable zinc ion battery. Angew. Chem. Int. Ed. 51, 933-935 (2012).

23. Pan, H. L. et al. Reversible aqueous zinc/manganese oxide energy storage from conversion reactions. Nat. Energy 1, 1639 (2016).

24. Zhang, N. et al. Rechargeable aqueous zinc-manganese dioxide batteries with high energy and power densities. Nat. Commun. 8, 405 (2017).

25. Sun, W. et al. $\mathrm{Zn} / \mathrm{MnO}_{2}$ battery chemistry with $\mathrm{H}^{+}$and $\mathrm{Zn}^{2+}$ coinsertion. $J$. Am. Chem. Soc. 139, 9775-9778 (2017).

26. Ingale, N. D., Gallaway, J. W., Nyce, M., Couzis, A. \& Banerjee, S. Rechargeability and economic aspects of alkaline zinc-manganese dioxide cells for electrical storage and load leveling. J. Power Sources 276, 7-18 (2015).

27. McLarnon, F. R. \& Cairns, E. J. The secondary alkaline zinc electrode. J. Electrochem. Soc. 138, 645-656 (1991).

28. Alfaruqi, M. H. et al. Enhanced reversible divalent zinc storage in a structurally stable $\alpha-\mathrm{MnO}_{2}$ nanorod electrode. J. Power Sources 288, 320-327 (2015).

29. Alfaruqi, M. H. et al. A high surface area tunnel-type $\alpha-\mathrm{MnO}_{2}$ nanorod cathode by a simple solvent-free synthesis for rechargeable aqueous zinc-ion batteries. Chem. Phys. Lett. 650, 64-68 (2016).

30. Lee, B. et al. Electrochemically-induced reversible transition from the tunneled to layered polymorphs of manganese dioxide. Sci. Rep. 4, 6066 (2014).

31. Lee, $B$. et al. Elucidating the intercalation mechanism of zinc ions into alpha$\mathrm{MnO}_{2}$ for rechargeable zinc batteries. Chem. Commun. 51, 9265-9268 (2015).

32. Alfaruqi, M. H. et al. Electrochemically induced structural transformation in a $\gamma-\mathrm{MnO}_{2}$ cathode of a high capacity zinc-ion battery system. Chem. Mater. 27, 3609-3620 (2015).

33. Alfaruqi, $\mathrm{M}$. H. et al. A layered $\delta-\mathrm{MnO}_{2}$ nanoflake cathode with high zincstorage capacities for eco-friendly battery applications. Electrochem. Commun. 60, 121-125 (2015).

34. Zhang, N. et al. Cation-deficient spinel $\mathrm{ZnMn}_{2} \mathrm{O}_{4}$ cathode in $\mathrm{Zn}\left(\mathrm{CF}_{3} \mathrm{SO}_{3}\right)_{2}$ electrolyte for rechargeable aqueous Zn-Ion battery. J. Am. Chem. Soc. 138 , 12894-12901 (2016).

35. Wei, C., Xu, C., Li, B., Du, H. \& Kang, F. Preparation and characterization of manganese dioxides with nano-sized tunnel structures for zinc ion storage. J. Phys. Chem. Solids 73, 1487-1491 (2012).
36. Lee, J., Ju, J. B., Cho, W. I., Cho, B. W. \& Oh, S. H. Todorokite-type $\mathrm{MnO}_{2}$ as a zinc-ion intercalating material. Electrochim. Acta 112, 138-143 (2013).

37. Jiang, B. et al. Manganese sesquioxide as cathode material for multivalent zinc ion battery with high capacity and long cycle life. Electrochim. Acta 229, 422-428 (2017).

38. Wang, Y. G. et al. A polyaniline-intercalated layered manganese oxide nanocomposite prepared by an inorganic/organic interface reaction and its high electrochemical performance for Li storage. Adv. Mater. 20, 2166-2170 (2008).

39. Kalubarme, R. S., Jadhav, H. S. \& Park, C. J. Electrochemical characteristics of two-dimensional nano-structured $\mathrm{MnO}_{2}$ for symmetric supercapacitor. Electrochim. Acta 87, 457-465 (2013).

40. Chigane, M. \& Ishikawa, M. Manganese oxide thin film preparation by potentiostatic electrolyses and electrochromism. J. Electrochem. Soc. 147, 2246-2251 (2000).

41. González, M. A., Trócoli, R., Pavlovic, I., Barriga, C. \& La Mantia, F. Layered double hydroxides as a suitable substrate to improve the efficiency of $\mathrm{Zn}$ anode in neutral pH Zn-ion batteries. Electrochem. Commun. 68, 1-4 (2016)

42. Sun, K. E. K. et al. Highly sustainable zinc anodes for a rechargeable hybrid aqueous battery. Chem. Eur. J. 24, 1667-1673 (2018).

43. Hsu, Y. K., Chen, Y. C., Lin, Y. G., Chen, L. C. \& Chen, K. H. Reversible phase transformation of $\mathrm{MnO}_{2}$ nanosheets in an electrochemical capacitor investigated by in situ Raman spectroscopy. Chem. Commun. 47, 1252-1254 (2011)

44. Polverejan, M., Viliegas, J. C. \& Suib, S. L. Higher valency ion substitution into the manganese oxide framework. J. Am. Chem. Soc. 126, 7774-7775 (2004).

45. Kim, Y. I., Page, K., Limarga, A. M., Clarke, D. R. \& Seshadri, R. Evolution of local structures in polycrystalline $\mathrm{Zn}_{1-x} \mathrm{Mg}_{x} \mathrm{O}(0 \leq x \leq 0.15)$ studied by Raman spectroscopy and synchrotron x-ray pair-distribution-function analysis. Phys. Rev. B 76, 115204 (2007).

46. Hadzic, B. et al. Raman study of surface optical phonons in hydrothermally obtained $\mathrm{ZnO}(\mathrm{Mn})$ nanoparticles. Opt. Mater. 58, 317-322 (2016)

\section{Acknowledgements}

The authors acknowledge funding support from the National Natural Science Foundation of China (21622303 and 21333002), National Key Research and Development Plan (2016YFB0901500 and 2016YFA0203302).

\section{Author contributions}

Y.W. conceived this idea and designed the experiments. Y.W. and Y.X. directed the project. J.H., Y.W. and Z.W. performed the material process and characterization. J.H., M.H., X.D. and Y.L. carried out the electrochemical measurements and data analysis. J.H. and Y.W. co-wrote the paper. All authors discussed the results and commented on the manuscript.

\section{Additional information}

Supplementary Information accompanies this paper at https://doi.org/10.1038/s41467018-04949-4.

Competing interests: The authors declare no competing interests.

Reprints and permission information is available online at http://npg.nature.com/ reprintsandpermissions/

Publisher's note: Springer Nature remains neutral with regard to jurisdictional claims in published maps and institutional affiliations.

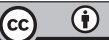

Open Access This article is licensed under a Creative Commons Attribution 4.0 International License, which permits use, sharing, adaptation, distribution and reproduction in any medium or format, as long as you give appropriate credit to the original author(s) and the source, provide a link to the Creative Commons license, and indicate if changes were made. The images or other third party material in this article are included in the article's Creative Commons license, unless indicated otherwise in a credit line to the material. If material is not included in the article's Creative Commons license and your intended use is not permitted by statutory regulation or exceeds the permitted use, you will need to obtain permission directly from the copyright holder. To view a copy of this license, visit http://creativecommons.org/ licenses/by/4.0/.

(c) The Author(s) 2018 